TINJAUAN PUSTAKA

\title{
Tatalaksana Perioperatif Ventilasi Mekanik pada Pasien dengan Gagal Jantung Kiri
}

\section{Perioperative Mechanical Ventilation Management in Left Heart Failure Patient}

\author{
Budi Nugroho ${ }^{凶}$, Yudi Hadinata \\ SMF Anestesi dan Perawatan Intensif Pascabedah, Rumah Sakit Jantung dan Pembuluh Darah \\ Harapan Kita, Jakarta, Indonesia \\ ${ }^{\bowtie}$ Korespondensi: dr.budinugroho@yahoo.co.id
}

\begin{abstract}
Heart failure is a condition of abnormalities in patients where the filling ability and heart pump function are impaired. Heart failure alone can occur acutely or chronically as well as potentially life-threatening. When the condition is worsening it can cause respiratory function disorders and worsening of the condition resulting to death. The condition of heart failure can be occure during surgical perioperative treatment requiring pharmacological therapy and non-pharmacological therapy. One of the modalities of non-pharmacological therapy that can help the heart pump function in conditions of heart failure is mechanical ventilation. This literature review will review perioperative mechanical ventilation therapy in patients with heart failure.
\end{abstract}

Keywords: heart pump; left heart failure; mechanical ventilation; perioperative; respiratory function disorders

\begin{abstract}
ABSTRAK
Penyakit gagal jantung merupakan suatu kondisi kelainan pada pasien dimana kemampuan pengisian dan fungsi pompa jantung mengalami gangguan. Gagal jantung sendiri dapat terjadi secara akut atau kronis serta berpotensi mengancam jiwa. Ketika kondisi tersebut memburuk maka dapat menyebabkan gangguan fungsi pernapasan dan perburukan kondisi hingga berakibat kematian. Kondisi gagal jantung dapat terjadi selama tindakan perawatan perioperatif pembedahan yang membutuhkan terapi farmakologi dan terapi non farmakologi. Salah satu modalitas terapi non farmakologi yang dapat membantu fungsi pompa jantung dalam kondisi gagal jantung adalah ventilasi mekanik. Tinjauan pustaka ini akan mengulas tentang terapi perioperatif ventilasi mekanik pada pasien dengan gagal jantung.
\end{abstract}

Kata Kunci: gagal jantung kiri; gangguan fungsi pernapasan; perioperatif; pompa jantung; ventilasi mekanik 


\section{PENDAHULUAN}

Penyakit gagal jantung merupakan suatu kondisi kelainan pada pasien dimana kemampuan pengisian dan fungsi pompa jantung mengalami gangguan. Gagal jantung sendiri dapat terjadi secara akut atau kronis serta berpotensi mengancam jiwa. Mortalitas pasien dengan kondisi gagal jantung telah mengalami penurunan dengan adanya kemajuan perawatan dan tindakan intervensi kardiovaskuler akan tetapi angkanya masih tinggi $10.4 \%$ hingga $42.3 \% .^{1}$ Gagal jantung dengan fungsi ventrikel ejeksi fraksi rendah merupakan salah satu faktor independen untuk terjadinya risiko komplikasi kardiovaskuler saat pasien menjalani tindakan anestesi dan pembedahan non jantung, dengan angka kejadian komplikasi infark jantung (14.9\%), eksaserbasi gagal jantung $(25.3 \%)^{2}$

Ketika kondisi gagal jantung selama masa perioperatif memberat maka dapat menyebabkan gangguan fungsi pernapasan hingga gagal napas yang mengakibatkan kematian, sehingga untuk menangani kondisi tersebut dibutuhkan terapi ventilasi mekanik sebagai salah satu terapi supportif non farmakologi yang dapat dioptimalkan selama masa perioperatif pembedahan untuk mengurangi beban kerja jantung pada pasien dengan gagal jantung.

\section{DEFINISI GAGAL JANTUNG}

Gagal jantung merupakan sindroma dari kumpulan gejala struktural atau fungsional dimana terjadi gangguan pengisian ventrikel serta pompa jantung untuk memompa darah. Tanda kardinal dari gagal jantung adalah mudah lelah serta sesak saat beraktivitas yang dapat menyebabkan keterbatasan aktivitas fisik, retensi cairan, yang mengarah pada kongestif dari paru, splanknik, serta edema perifer. Beberapa pasien dapat menunjukkan gejala retensi cairan sementara pasien lain hanya mengalami keterbatasan aktifitas serta mudah lelah tanpa gejala kongestif. Sindroma gagal jantung ini dapat timbul sebagai akibat dari kelainan yang terjadi pada pericardium, miokardium, endokardium, katup jantung, pembuluh darah besar, atau gangguan metabolik tertentu. Keluhan utama yang dirasakan pasien terutama dikarenakan penurunan dari fungsi ejeksi ventrikel kiri. ${ }^{2,3,4}$

\section{Klasifikasi Gagal Jantung}

Klasifikasi gagal jantung berdasarkan kriteria American College of Cardiology Foundation/American Heart Association (ACCF/AHA) dibagi menjadi gagal jantung dengan fungsi ejeksi fraksi ventrikel lebih dari $40 \%$ (Preserved) dan gagal jantung dengan fungsi ejeksi ventrikel kurang dari $40 \%$ (Reduced) ${ }^{4}$

Tabel 1. Definisi gagal jantung

\begin{tabular}{|c|c|c|}
\hline Klasifikasi & $\begin{array}{l}\text { EF } \\
(\%)\end{array}$ & Keterangan \\
\hline $\begin{array}{l}\text { I. Gagal jantung dengan } \\
\text { penurunan (reduced) } \\
\text { ejeksi fraksi (HFrEF) }\end{array}$ & $\leq 40$ & $\begin{array}{l}\text { Dikenal dengan gagal jantung sistolik. Studi yang } \\
\text { melibatkan pasien HFrEF, pada populasi pasien ini studi } \\
\text { mengenai efikasi terapi telah banyak dilakukan secara } \\
\text { RCT. }\end{array}$ \\
\hline $\begin{array}{l}\text { II. Gagal jantung dengan } \\
\text { preserved ejeksi fraksi } \\
(\mathrm{HFpEF})\end{array}$ & $\geq 50$ & $\begin{array}{l}\text { Dikenal dengan gagal jantung diastolik. Beberapa kriteria } \\
\text { telah digunakan untuk mendefinisikan HFpEF. Diagnosa } \\
\text { HFpEF sangat sulit dilakukan karena harus } \\
\text { mengeksklusikan berbagai penyebab simtomatis dari }\end{array}$ \\
\hline
\end{tabular}


a. HFpEF, borderline

41 to

49

b. HFpEF, improved $>40$ gagal jantung nonkardiak. Hingga sekarang terapi yang efektif belum dapat diidentifikasi.

Populasi pasien ini ada pada ambang batas atau kelompok intermediet. Karakteristik dari kelompok tersebut, pola tatalaksana, dan hasil akhir dari pengobatan sama seperti populasi pasien $\mathrm{HFpEF}$

Telah diketahui sebelumnya bahwa pada pasien dengan diagnosa HFpEF sebelumnya telah didiagnosa dengan kondisi HFrEF. Populasi pasien ini mengalami perbaikan fungsi ejeksi fraksi selama perawatan dan secara klinis berbeda dengan populasi yang persisten bertahan dengan ejeksi fraksinya atau yang mengalami penurunan fungsi ejeksi fraksi.

Dikutip dari: Clyde, dkk.

\section{Fisiologi Pernapasan}

Paru merupakan organ tubuh yang menerima seluruh darah yang dipompakan oleh jantung untuk melakukan pertukaran gas oksigen dan karbondioksida serta fungsi metabolik. ${ }^{5}$

Proses ventilasi pada paru yaitu inspirasi dan ekspirasi dipengaruhi oleh kondisi struktur anatomi dari jalan napas serta bantuan dari rongga dinding dada yang dibentuk oleh tulang iga serta bantuan dari otot-otot pernapasan. Perubahan volume pernapasan selama proses inspirasi dan ekspirasi dapat diketahui dengan alat bantu spirometri dan dapat dipelajari dari pola gambar berikut. ${ }^{5,6}$

Hubungan antara fungsi paru sebagai organ pernapasan yang berfungsi menerima aliran darah dari jantung dan melakukan fungsi pernapasan serta berada pada rongga dada bersama-sama dengan jantung mengakibatkan perubahan kondisi anatomi dan fungsi pada masing-masing organ saling berpengaruh satu sama lain atau disebut sebagai heart-lung interaction. ${ }^{5,6}$

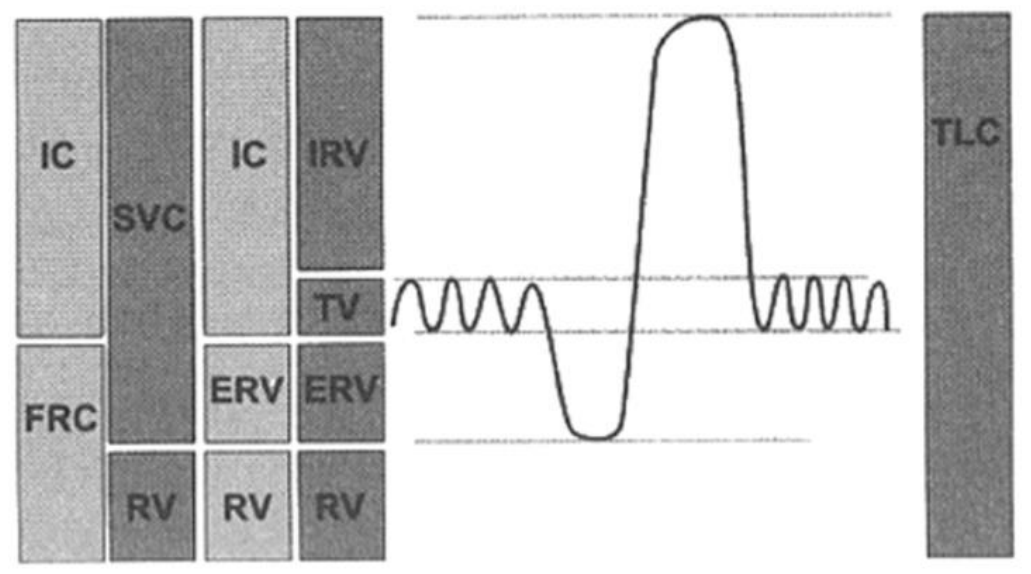

Gambar 1. Volume paru

$\mathrm{ERV}=$ expiratory reserve volume; $\mathrm{FRC}=$ functional residual capacity; $\mathrm{IC}=$ inspiratory capacity; $\mathrm{IRV}=$ inspiratory reserve volume; $\mathrm{RV}=$ residual volume; $\mathrm{SVC}=$ slow vital capacity; $\mathrm{TLC}=$ total lung capacity; TV=tidal volume.

Dikutip dari Judd D. Flesch. ${ }^{6}$ 


\section{Efek Ventilasi Mekanik pada Gagal Jantung Kiri}

Kondisi gagal jantung kiri merupakan ketidakmampuan ventrikel kiri untuk berkontraksi dan memompa darah ke seluruh tubuh guna memenuhi perfusi organ. Tanda klinis yang ditemukan berupa tekanan darah yang rendah serta gangguan perfusi organ seperti penurunan kesadaran, disfungsi organ splanknik, dan penurunan produksi urin. Penggunaan ventilasi mekanik pada gagal jantung kiri dapat dapat membantu untuk mengurangi tahahan (afterload) jantung kiri, mnegurangi kebutuhan oksigen pada jantung, meningkatkan cardiac output, dan mengurangi beban kerja pernapasan sehingga menurunkan kebutuhan oksigen secara keseluruhan. ${ }^{7}$

\section{Pengaturan PEEP pada Gagal Jantung Kiri}

Ventilasi mekanik dengan penggunaan Positive end expiratory pressure (PEEP) merupakan tekanan positif yang diberikan pada akhir pernapasan untuk menjaga agar alveoli paru tidak kolaps sehingga paru tidak mengalami akteletasis. Penggunaan PEEP bermanfaat agar proses difusi oksigen dan karbondioksida tetap dapat berlangsung di alveoli paru, selain itu dampak lain dari penggunaan PEEP adalah penurunan dari venous return atau pengisian jantung. Kondisi preload yang berkurang ini dapat memberikan keuntungan pada kondisi gagal jantung kiri. Tekanan positif intratorakal dari PEEP pada alveoli paru akan ditransmisikan pada level arteri pulmonal, ventrikel kanan, hingga ke atrium kanan. Kondisi tersebut akan menyebabkan tekanan atrium kanan yang lebih positif sehingga aliran darah balik dari seluruh tubuh yang akan bermuara di atrium kanan melalui pembuluh vena kava inferior dan superior (IVC dan SVC) akan terhambat sehingga dampaknya terjadi pengurangan pengisian volume darah ke jantung. Pada kondisi gagal jantung kiri maka pengurangan preload ke jantung kiri dapat bermanfaat untuk menjaga agar ventrikel kiri tidak mengalami kelebihan volume dan memberikan kesempatan agar jantung bisa berkontraksi lebih baik. Pengaruh PEEP sendiri juga bermanfaat agar paru-paru tidak mengalami kongestif akibat dampak dari tekanan positif yang mendorong cairan dari alveoli dan interstisium paru kembali ke vaskular paru. PEEP juga bermanfaat untuk menurunkan tahanan ventrikel kiri ( $L V$ afterload) dengan cara merubah gradient tekanan transmural. Penggunaan PEEP akan menyebabkan tekanan pleura lebih positif sehingga akan menurunkan tekanan transmural ventrikel kiri, dimana tekanan transmural ventrikel kiri merupakan gradient tekanan saat fase sistolik ventrikel kiri dengan tekanan intratorakal yang dipengaruhi terutama oleh tekanan pleura. ${ }^{8}$

Perubahan penurunan afterload ventrikel kiri dalam kasus gagal jantung kiri akan dapat bermanfaat untuk membantu ventrikel kiri lebih mudah memompa darah keseluruh tubuh, akan tetapi penggunaan PEEP yang terlalu tinggi juga dapat meningkatkan tahanan dari jantung kanan sehingga menyebabkan beban kerja ventrikel kanan menjadi lebih berat pada kondisi pasien dengan gagal jantung kanan atau hipertensi pulmonal. Secara umum penggunaan PEEP pada status volume yang tidak adekuat atau kondisi hipovolemik akan menyebabkan penurunan preload yang lebih berat dan mengurangi curah jantung kanan dan kiri. Pemberian PEEP sebesar $5 \mathrm{cmH}_{2} \mathrm{O}$ pada pengaturan ventilasi mekanik dapat mengurangi beban kerja pernapasan hingga $40 \% .{ }^{9}$ 


\section{Pengaturan Volume Tidal pada Gagal Jantung Kiri}

Bantuan ventilasi mekanik dengan pengaturan volume tidal atau pemanfaatan tekanan positif inspirasi pada kasus gagal jantung dapat membantu mengurangi kebutuhan oksigen dari kerja otot pernapasan. Pemberian tekanan positif juga dapat membantu untuk mendorong kembali cairan yang terakumulasi di alveoli ke interstisium dan kembali ke vaskuler pada kasus edema paru sehingga difusi oksigen akan berjalan lebih baik. Pengaturan ventilasi mekanik yang sesuai akan dapat memberikan keuntungan dalam mengurangi beban kerja jantung melalui pengurangan kebutuhan oksigen otot pernapasan tanpa menyebabkan penurunan pengisian jantung (preload) karena inflasi paru yang berlebih. Pemberian tekanan inspirasi positif sebesar 5 $\mathrm{cmH}_{2} \mathrm{O}$ dapat mengurangi kerja otot pernapasan sebesar $31-38 \%$ dari kondisi pernapasan normal, sementara pemberian tekanan inspirasi positif sebesar $10 \mathrm{~cm} \mathrm{H}_{2} \mathrm{O}$ dapat mengurangi beban kerja pernapasan sebesar 46$60 \%$. ${ }^{9}$ Pengaturan tekanan inspirasi yang sesuai dengan target pencapaian tidal volume 6-8 cc/KgBB dari berat badan prediktif dapat memberikan keuntungan dengan menghindari risiko terjadinya kerusakan alveoli paru hingga barotrauma atau volutrauma. ${ }^{10,11}$

\section{Pengaturan Plateau Pressure pada Gagal Jantung Kiri}

Salah satu hal yang harus diperhatikan pada pengaturan ventilasi mekanik adalah tekanan plateau. Tekanan plateau didefinisikan sebagai tekanan pada sirkuit pernapasan mekanik hingga alveoli pada akhir fase inspirasi yang mencegah alveoli mengalami kolaps dimana tekanan ini sebanding dengan tekanan komplians dari dinding dada. Secara umum dengan menjaga tekanan plateau antara 25-30 $\mathrm{cm} \mathrm{H}_{2} \mathrm{O}$ maka diharapkan dapat mencegah terjadinya barotrauma atau volutrauma. Pada kondisi gagal jantung dapat terjadi perubahan komplians paru dimana terdapat kondisi kongestif paru serta efusi pleura. Perubahan tekanan intrapleura yang disebabkan karena efusi pleura dapat merubah tekanan transpulmonal karena dampak dari efusi yang menghambat ekspansi paru saat fase inpirasi, sehingga pengaturan ventilasi mekanik harus memperhatikan kondisi tersebut untuk mencegah trauma pada alveoli paru. ${ }^{12,13}$

\section{Pengaturan Fraksi Oksigen $\left(\mathrm{FiO}_{2}\right)$ pada Kondisi Gagal Jantung Kiri}

Pengaturan suplemen oksigen selama ventilasi mekanik dengan merubah fraksi inspirasi oksigen $\left(\mathrm{FiO}_{2}\right)$ dapat bermanfaat untuk mengatasi hipoksia alveolar selama kondisi hypoxemia di dalam darah terjadi, akan tetapi pemberian fraksi oksigen tinggi lebih dari $50 \%$ juga dapat menyebabkan pembentukan radikal bebas oksigen. ${ }^{14}$ Dari literatur yang ditunjukkan oleh Nakamura, dkk. ${ }^{15}$ pemberian tambahan oksigen fraksi tinggi pada kondisi gagal jantung dapat menyebabkan kerusakan otot jantung lebih lanjut melalui pembentukan radikal bebas yang mengarah pada proses apoptosis serta peningkatan kadar kalsium intraseluler. Pemberian fraksi oksigen tinggi juga dapat meningkatkan preload jantung kiri yang dapat membebani jantung kiri karena preload berlebih melalui mekanisme vasodilatasi pembuluh darah paru pulmonal. 


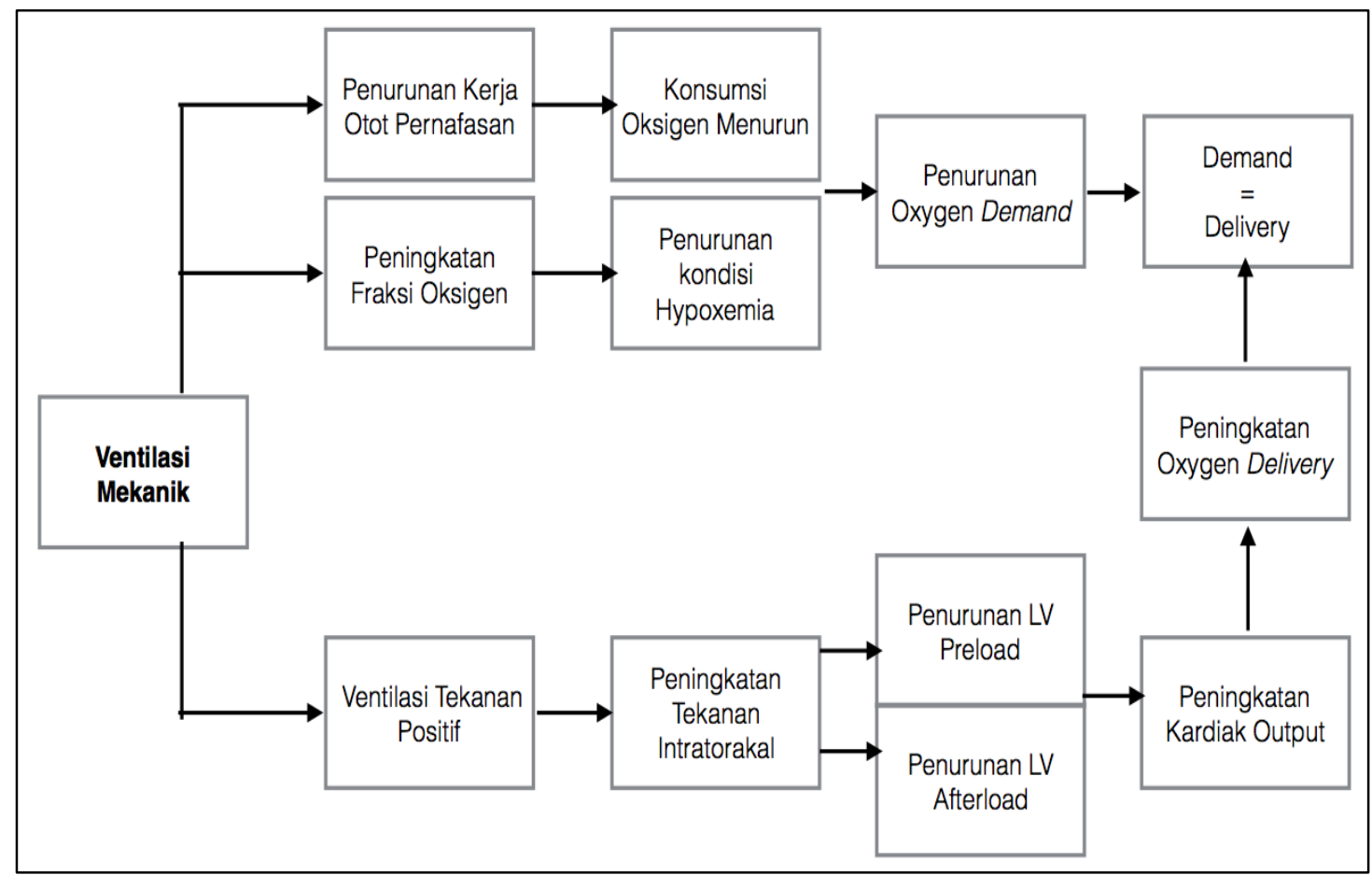

Gambar 2. Alur efek ventilasi mekanik pada gagal jantung kiri

\section{RINGKASAN}

Ventilasi mekanik merupakan modalitas terapi non farmakologi yang dapat dimanfaatkan dalam perawatan pasien dengan kondisi gagal jantung selama perioperatif pembedahan umum dan kardiak. Pengaturan yang sesuai dengan kebutuhan masing-masing pasien dapat memberikan keuntungan dengan mengurangi beban jantung dan konsumsi oksigen dari otot pernapasan. Selain itu pengaturan ventilasi mekanik yang minimal juga dapat mengurangi risiko barotrauma atau volutrauma tanpa mengurangi pengisian volume jantung.

\section{DAFTAR PUSTAKA}

1. Emelia J. Benjamin, Salim S. Virani, Clifton W. Callaway, et. al. Heart Disease and Stroke Statistics2018 update, a Report From the American Heart Association. AHA Journal of Circulation. 2018; 137:p67-p492

2. Kirsten O. Healy MD, Carol A. Waksmonski MD, Robert K.
Altman MD, et. al. Perioperative Outcome and Long-Term Mortality for Heart Failure Patients Undergoing Intermediate and High Risk Noncardiac Surgery: Impact of Left Ventricular Ejection Fraction. 2010. Congestive Heart Failure, Wiley Periodicals. Inc;16:p45-9

3. Hensley FA, Martin DE, Gravlee GP. Cardiac anesthesia. edisi ke-5. Philadelphia:Lippincot Williams \& Wilkins; 2013, p481-5

4. Clyde W. Yancy, Marriel Jessup, Biykem Bozkurt, et. al. ACCF/AHA Guideline for the Management of Heart Failure, A Report of the American College of Cardiology Foundation/American Heart Association Task Force on Practice Guidelines. AHA Journal of Circulation. 2013; 128: p242-p327

5. Joel A. Kaplan, Peter D. Slinger. $3^{\text {rd }}$ Edition. Thoracic Anesthesia. 2003. Churchil Livingstone, USA: 3: p5769 
6. Judd D. Flesch MD, C. Jessica Dine MD. Lung Volumes. CHEST Journal. 2012; 142(2): p506-10

7. Miller JD, Smith CA, Hemauer SJ, et. al. The effects of inspiratory intrathoracic pressure production on the cardiovascular response to submaximal exercise in health and chronic heart failure. Am. J. Physiol Heart Circ. Physiol. 2007; 292: p580-92

8. Luecke T, Pelosi P. Clinical review: Positive end-expiratory pressure and cardiac output. Critical Care. 2005; 9:p607-21

9. Tobin MJ. Extubation and the Myth of Minimal Ventilator Settings. Am. J. Respir. Crit. Care Med. 2012; 185: p349-50

10. Romagnoli S, Ricci Z. Lung protective ventilation in Cardiac Surgery. Heart Lung Vessel. 2015; 7: p5-6

11. Futier E, Constantin JM, Paugam
Burtz C, et. al. A trial of intraoperative low-tidal-volume ventilation in șÉp.abdominal surgery. N. Engl. J. Med. 2013, 369:p428-37

12. Brower RG, Matthay MA, Morris A, et. al. The Acute Respiratory Distress Syndrome Network. Ventilation with lower tidal volumes as compared with traditional tidal volumes for acute lung injury and the acute respiratory distress syndrome. N. Engl. J. Med. 2000; 342: p1301-08

13. Slutsky AS, Ranieri VM. Ventilator-Induced Lung Injury. $N$. Engl. J. Med. 2013; 369:p2126-36

14. Jackson RM. Pulmonary oxygen toxicity. Chest $1985 ; 88: \mathrm{p} 900-5$

15. Nakamura K, Murakami M, Miura D, et. al. Beta-Blockers and Oxidative Stress in Patients with Heart Failure. Pharmaceuticals 2011; 4: p1088-100 